\title{
Treatment-Seeking Problem Gamblers: Characteristics of Individuals Who Offend to Finance Gambling
}

\section{Amanda Roberts ${ }^{1}$ (D) Stephen Sharman ${ }^{2} \cdot$ Matthew King ${ }^{3} \cdot$ Andy Bayston ${ }^{4}$. Henrietta Bowden-Jones ${ }^{4,5}$}

Published online: 19 December 2019

(C) The Author(s) 2019

\begin{abstract}
The relationship between crime and gambling is well established; however, few studies have examined offending specifically to finance gambling within a UK gambling treatment-seeking population. A total of 1226 treatment-seeking gamblers completed the Problem Gambling Severity Index (PGSI), Patient Health Questionnaire and the Generalized Anxiety Disorder 7 item scale, and were asked whether they had committed any illegal behaviours to finance gambling. A total of $42.5 \%$ reported offending behaviour. A greater proportion of the offending group was single or married/cohabiting, had a lower level qualifications, lower income, had experienced childhood abuse, family mental health problems and gambling-related harms compared with the non-offending group. Offenders reported higher anxiety, depression and disordered gambling scores. Disordered gamblers who offend make up a discrete and complex subgroup with distinct vulnerabilities. Findings will be useful to clinicians involved in the assessment and management of problematic gambling. Gamblers who offend to finance gambling may have different treatment needs and treatment providers should administer appropriate clinical interventions to address vulnerabilities.
\end{abstract}

Keywords Gambling · Disordered Gambling · Illegal behaviour - Crime · Mental Health ·

Treatment

Amanda Roberts

aroberts@lincoln.ac.uk

1 School of Psychology, College of Social Science, University of Lincoln, Brayford Pool, Lincoln, Lincolnshire LN6 7TS, UK

2 School of Psychology, University of East London, London, Stratford E15 4LZ, UK

3 Barnet, Enfield and Haringey Mental Health Trust, North London Forensic Service, Chase Farm Hospital, The Ridgeway, Enfield EN2 8JL, UK

4 National Problem Gambling Clinic, 69 Warwick Rd, London, Fulham SW5 9BH, UK

5 Department of Medicine, Imperial College, London, South Kensington Campus, London SW7 2AZ, UK 
Approximately $2.3 \%$ of the world's population experience problems with gambling (Williams et al. 2012) and for many, gambling problems can evolve into disordered gambling (Wardle et al. 2011). Disordered gambling is classified as a behavioural addiction (American Psychiatric Association 2013) and is characterised by a condition that leads to family, social, personal or recreational pursuits being compromised, disrupted or damaged by continuing maladaptive behaviour (Delfabbro 2013). The disorder often results in serious negative consequences including illegal activities and crime (Lahn 2005), mental health problems (Lorains et al. 2011), financial crises (Grant et al. 2010), domestic violence, (Roberts et al. 2016, 2018), homelessness (Sharman et al. 2015) and self-harm/ suicide (Ledgerwood and Petry 2004), and tends to cluster with other high-risk behaviours such as alcohol and substance misuse (Petry 2005).

Several studies have shown that prisoners tend to be impulsive and poor decision-makers in risky situations with a reduced sense of regret (Hughes et al. 2014; Pachur et al. 2010; Varghese et al. 2014; Yechiam et al. 2008). This may explain not only participation in criminal behaviour but also why the prevalence of gambling is much higher than in the general population; as disordered gambling severity escalates, illegal behaviour has also been shown to increase (Lahn 2005). The prevalence of disordered gambling in forensic populations is high (Lai 2014; Turner et al. 2013; Williams et al. 2005). In a recent UK study, the prevalence of disordered gambling in prisons was found to be significantly higher than in the general population at $12.1 \%$ (compared with $0.7 \%$ (Wardle et al. 2011)) (May-Chahal et al. 2017). International studies have reported even higher prevalence rates; in New Zealand, Abbott et al. (2005) reported that $21 \%$ of prisoners were probable lifetime disordered gamblers; and in Australia, it has been acknowledged that as many as $60 \%$ of prisoners have a lifetime gambling disorder with $18 \%$ reporting they were incarcerated due to offending relating to their gambling problem (Riley et al. 2018). In a study conducted in Canada, up to $65.2 \%$ of severe problem gamblers reported gambling-related criminal behaviour (Turner et al. 2009). The majority of perpetrated crimes within disordered gamblers are motivated by gambling either to finance gambling activities or to pay off gambling debts (Rosenthal and Lesieur 1996; Zorland et al. 2008).

Criminal activity is also common within non-forensic clinical gambler populations. Previous research suggests that almost half of all disordered gamblers participate in criminal activities (Zorland et al. 2008). For example, in North America, offending behaviour was assessed in a sample of problem gamblers who contacted a gambling helpline and $43.7 \%$ reported committing criminal acts directly related to gambling (Potenza et al. 2001). Likewise, Lorenz et al. (1990) found that $61 \%$ of problem gamblers in Maryland had engaged in gambling-related illegal activities. In studies of 60 Gamblers Anonymous attendees in Canada, 68\% of gamblers indicated that they had engaged in illegal activities, and $17 \%$ of gamblers had appeared in court as a consequence of gambling-related crime (Ladouceur et al. 1994). In Germany, 54.5\% of attendees at a gamblers anonymous group indicated they had engaged in illegal activities, and $46 \%$ of attendees disclosed committing crimes entirely to support gambling (Meyer and Fabian 1992). Folino and Abait (2009) found that $32 \%$ callers to a gambling helpline admitted participating in some sort of illegal exploit due to gambling and this number rose to $76 \%$ in those attending Gamblers Anonymous (GA). In the UK, one study identified the proportion of both reported and unreported crimes amongst gamblers attending GA was between 77 and 82\% (Brown 1987). Furthermore, reported prevalence rates may be underreported as many of the crimes remain either undetected (Adolphe et al. 2019) or may be committed against persons unlikely to press charges (e.g. family members) (Sakurai and Smith 2003).

It has been suggested that crime may be an indicator of the severity of disordered gambling (Folino and Abait 2009; Bowden-Jones 2013). Previous studies have found 
more severe lifetime and recent gambling symptomology in those with offending behaviour (Ledgerwood et al. 2007). Likewise, it has been recognised that gamblingrelated criminality is usually seen in patients with the most severe clinical profiles. Specifically, problematic drug and alcohol use have been associated with an increased likelihood of both engagement in illegal behaviours and the risk of gambling-related arrest (Potenza et al. 2000, 2005). Similarly, problem gamblers with a history of arrest are more likely to have antisocial personality disorder (Potenza et al. 2000) and depression (Momper et al. 2010), and individuals who engage in gambling-related crime are more likely to have experienced suicidality (Ledgerwood et al. 2005).

Despite the global expansion of commercial gambling environments and documented associations with criminality, no relevant studies of clinical populations comprising individuals attending a problem gambling (outpatient) treatment clinic in the UK have been reported as far as we are aware. Evidence for the association between gambling and criminality mainly comes from forensic populations (e.g. Abbott and McKenna 2005; Abbott et al. 2005; May-Chahal et al. 2017; Preston et al. 2012; Turner et al. 2009), with considerably fewer studies carried in clinical populations, which are outside the UK (e.g. Mestre-Bach et al. 2018a, b; Blaszczynski and McConaghy 1994). Moreover, very few clinical studies have asked whether the criminal activity was instrumentally carried out to finance gambling.

The broad aim of this study was to better understand the relationship between gambling and criminality by comparing those who have offended to finance gambling (in a lifetime) to those who have not, in a large sample of individuals seeking treatment for gambling problems. More specifically, the study aimed to:

1) Examine the prevalence of criminal behaviour committed to finance gambling, among both males and females seeking treatment at a clinic for gambling disorder in the UK; and

2) Establish whether clients reporting such offending behaviour could be distinguished from those that did not in terms of a range of clinical characteristics to signal vulnerabilities to disordered gambling; it was predicted that criminal behaviour to finance gambling would be associated with a more severe clinical profile. More specifically, those with a criminal history would score more highly on the PGSI, the PHQ-9 and GAD-7, indicating an increased severity of gambling, depression and anxiety.

3) Evaluate whether clients reporting such offending behaviour could be distinguished from those that did not in terms of gambling-related variables. It was predicted that criminal behaviour committed to finance gambling would be associated with more extreme gambling-related activity (i.e. higher expenditure and time spent gambling, higher debt, a history of parental gambling and earlier age of onset) and more damage and disruption though gambling to relational and professional pursuits.

\section{Method}

\section{Sample}

The study was based on routine data collected from individuals seeking treatment at the National Problem Gambling Clinic (NPGC), part of the Central North-West London 
National Health Service (NHS) Trust, UK, from 2011 until 2015 (4 years). The sample of $n=1226$ comprised 1128 males $(92.0 \%)$ and 98 females $(8.6 \%)$, with an average age of $35.6(\mathrm{SD}=10.9)$. Clients were referred from a number of different sources including self-referral, family members, general practitioners and other healthcare professionals. The only inclusion criterion was that patients were classified as problem gamblers (scoring $8+$ on the PGSI-see below). The demographic characteristics of the sample are shown in Table 1.

\section{Measures}

\section{Problem/Pathological Gambling}

Problem Gambling Severity Index The PGSI is a 9-item self-report tool that measures gambling problem severity (Ferris and Wynne 2001). The scale assesses problematic gambling behaviour alongside interrelated adverse consequences and harms. The items are scored from 0 to $3(0=$ never, $1=$ sometimes, $2=$ most of the time, $3=$ almost always). The PGSI is scored out of 27. The scale has good internal reliability (Cronbach's $\alpha=0.84$ ) (Ferris and Wynne 2001), and more recent studies have reported excellent internal consistency reliability (Cronbach's $\alpha=.90$ ) (Williams and Volberg 2014).

\section{Offending Behaviour}

Participants were asked whether they had committed any illegal behaviours to finance gambling. This included unreported crime, crime reported to the police and any previous convictions/sentences. Offending behaviour to finance gambling was coded as positive when participants answered yes to any part of the question.

Table 1 Demographics

\begin{tabular}{|c|c|c|c|c|c|c|}
\hline \multirow[t]{2}{*}{ Variable } & \multicolumn{2}{|c|}{ Non-offending } & \multicolumn{2}{|c|}{ Offending } & \multirow[t]{2}{*}{ Statistical test } & \multirow[t]{2}{*}{$P$ value } \\
\hline & $n$ & $\%$ & $n$ & $\%$ & & \\
\hline \multicolumn{7}{|l|}{ Gender } \\
\hline Male & 646 & 91.60 & 482 & 92.50 & \multirow[t]{2}{*}{$\chi^{2}(1, n=1226)=0.318$} & \multirow[t]{2}{*}{0.573} \\
\hline Female & 59 & 8.40 & 39 & 7.50 & & \\
\hline \multicolumn{7}{|l|}{ Marital status } \\
\hline Single & 320 & 49.50 & 269 & 56.60 & $\chi^{2}(1, n=1121)=5.528$ & 0.019 \\
\hline Married/cohabiting & 281 & 43.50 & 168 & 35.40 & $\chi^{2}(1, n=1121)=7.535$ & 0.006 \\
\hline Divorced/separated/widowed & 45 & 6.70 & 37 & 7.80 & $\chi^{2}(1, n=1121)=0.530$ & 0.466 \\
\hline \multicolumn{7}{|l|}{ Education } \\
\hline No qualifications & 71 & 12.10 & 83 & 18.80 & $\chi^{2}(1, n=1029)=9.012$ & 0.003 \\
\hline GCSE/O-level/A-level & 236 & 40.10 & 227 & 51.50 & $\chi^{2}(1, n=1029)=13.089$ & 0.001 \\
\hline \multirow[t]{2}{*}{ University/professional } & 281 & 47.80 & 131 & 29.70 & $\chi^{2}(1, n=1029)=34.327$ & 0.001 \\
\hline & \multicolumn{2}{|c|}{ Median (IQR) } & \multicolumn{2}{|c|}{ Median (IQR) } & & \\
\hline Yearly income & \multicolumn{2}{|c|}{$£ 22,200(£ 21,800)$} & \multicolumn{2}{|c|}{$£ 16,000(£ 17,270)$} & $U=63,296$ & 0.001 \\
\hline Age & \multicolumn{2}{|c|}{$33.5(14)$} & \multicolumn{2}{|c|}{$33.0(15)$} & $U=179,922$ & 0.515 \\
\hline
\end{tabular}




\section{Previous Mental Health Diagnosis}

Participants were asked if they had even been diagnosed with a mental health diagnosis. This included substance misuse, psychosis, mood disorders, personality disorder or a learning disability/ developmental disorder.

\section{Current Depression}

Patient Health Questionnaire-9 The PHQ-9 is a widely used 9-item instrument which scores each of the 9 DMS-IV criteria for depression (Kroenke et al. 2001). Items are scored from 0 to $3(0=$ not at all; 1 = several days; $2=$ more than half the days; $3=$ nearly every day). Scores range from 0 to 27. It has been commended for its high sensitivity and specificity for assessing severity of depression in several populations with a Cronbach's $\alpha$ of 0.89 and 0.86 (Kroenke et al. 2001).

\section{Current Anxiety Disorder}

Generalized Anxiety Disorder-7 Item Scale The GAD-7 is a widely used 7-item brief measure of generalized anxiety disorder that has been found to have good sensitivity and specificity for GAD (Cronbach $\alpha=.92$; Spitzer et al. 2006). Questions are scored from 0 to 3 $(0=$ not at all $1=$ several days; $2=$ more than half the days; $3=$ nearly every day $)$. Scores range from 0 to 21 (Spitzer et al. 2006).

\section{Monetary Debts and Losses}

Participants were asked questions about their estimated current, monthly and total debts through gambling using an open response format.

\section{Childhood Trauma}

Clients were asked if they had ever experienced childhood abuse. This included physical, sexual and emotional abuse. Multiple abuses were coded when clients indicated that they had experienced all three types of abuse.

\section{Gambling History}

Clients were asked the age they first gambled, whether there was a history of parental gambling, and whether they had an early big win. They were also asked to estimate the number of days gambled in the past month, to confirm whether they had previously received treatment for disordered gambling and whether they had lost a relationship or job of gambling.

\section{Sociodemographic Measures}

Data collected (categorisation in parentheses) included the following: gender (male, female), age, marital status (single, married/cohabiting, divorced/separated/widowed), education (no qualifications, GCSE/O-Level/A-Level, university/professional). 


\section{Procedure}

Data was collected between March 2011 and March 2015 from clients who were voluntarily seeking treatment at the National Problem Gambling Clinic (NPGC). All clients entering the service during the study period completed the questionnaires prior to meeting with a clinician for their first appointment. The questionnaire included the PGSI and the clinical scales (PHQ-9, GAD-7, AUDIT-C) and the questions listed above. Demographic details were collected from a referral form completed by the clients prior to assessment. During the study period, 100\% clients (1226 participants) consented to the use of their data. All participants were subsequently classified as problem gamblers (scoring 8 or more on the PGSI). All data was collected in accordance with NHS regulations of standard clinical practice.

\section{Statistical Analysis}

Once subjects had been identified, they were separated into two groups - no offending committed to finance gambling (non-offending group) $(n=705,57.5 \%)$ and offending committed to finance gambling (offending group) ( $n=521,42.5 \%)$. The groups were then compared in the following areas - demographics, psychiatric and family history, and clinical scores (PGSI, PHQ, GAD-7 scores) and gambling history.

Standard descriptive statistics were produced in order to characterize our sample. Please note that not all categories total $100 \%$ because of missing data. Significant differences between our populations were determined using the Mann-Whitney $U$ test (for ordinal variables) or $\chi^{2}$ test (for categorical variables) as appropriate. All analyses of data were carried out using Statistical Package for the Social Sciences (SPSS) 22.0. A significance level of 5\% was adopted for all analyses.

\section{Results}

The overall prevalence of offending behaviour to finance gambling reported in those presenting to the NPGC was $42.5 \%$ (42.7\% of males and $39.8 \%$ of females). There was no significant difference in age or gender between the group who had offended and those who had not. A greater proportion of the offending group was single or not married/cohabiting and had a lower level/no qualification compared with those who had not offended to finance gambling. The median salary earnings in the offending group were significantly less than the non-offending group: $£ 6000+$ a year less (see Table 1).

High rates of mental illness were found in both groups (Table 2). There was a statistically significant increase in a mental health diagnosis, a family history of mental health problems and previous gambling disorder treatment within the group who has offended to finance gambling. Moreover, a higher proportion of those in the offending group had experienced childhood abuse, specifically sexual abuse and multiple abuses compared with the nonoffending group. A series of further Mann-Whitney $U$ test showed clients who had offended to finance gambling scored significantly higher on the clinical measures (see Table 3); specifically, they had significantly higher median scores on the PGSI (indicating higher gambling severity) and the PHQ-9 and GAD-7 (indicating more severe depression and anxiety).

Overall, those who reported offending behaviour to finance gambling started gambling at a significantly significant earlier age (by 2 years) and had gambled more days in the month 
Table 2 Psychiatric and family history

\begin{tabular}{|c|c|c|c|c|c|c|}
\hline \multirow[t]{2}{*}{ Variable } & \multicolumn{2}{|c|}{ Non-offending } & \multicolumn{2}{|c|}{ Offending } & \multirow[t]{2}{*}{ Statistical test } & \multirow[t]{2}{*}{$P$ value } \\
\hline & $n$ & $\%$ & $n$ & $\%$ & & \\
\hline Mental health diagnosis & 206 & 31.60 & 209 & 45.30 & $\chi^{2}(1, n=1112)=21.631$ & 0.001 \\
\hline Childhood abuse & 97 & 14.10 & 122 & 24.10 & $\chi^{2}(1, n=1194)=19.258$ & 0.001 \\
\hline Physical abuse & 40 & 5.80 & 43 & 8.50 & $\chi^{2}(1, n=1194)=3.188$ & 0.074 \\
\hline Sexual abuse & 9 & 1.30 & 25 & 4.90 & $\chi^{2}(1, n=1194)=13.825$ & 0.001 \\
\hline Emotional abuse & 30 & 4.40 & 27 & 5.30 & $\chi^{2}(1, n=1194)=0.059$ & 0.443 \\
\hline Multiple abuse & 18 & 2.60 & 27 & 5.30 & $\chi^{2}(1, n=1194)=5.887$ & 0.015 \\
\hline Family history of mental health problems & 222 & 32.40 & 218 & 43.10 & $\chi^{2}(1, n=1192)=14.374$ & 0.001 \\
\hline Previous Gambling Disorder treatment & 332 & 56.70 & 298 & 66.80 & $\chi^{2}(1, n=1032)=10.995$ & 0.001 \\
\hline
\end{tabular}

before treatment started (Table 4). The offending group was more likely to have lost a job and a relationship due to gambling. Between groups, there was no significant difference between amount of current debt and the median total losses.

\section{Discussion}

This study adds to growing evidence demonstrating a relationship between disordered gambling and criminality. To our knowledge, this is the first study to compare sociodemographic, gambling behaviour specific and clinical variables in treatment-seeking gamblers within the UK who had offended to finance gambling compared with those who had not. Overall, $42.5 \%$ of participants had engaged in offending to finance gambling, largely consistent with overall offending behaviour the small amount of treatment-based international studies (e.g. Blaszczynski and McConaghy 1994; Meyer and Fabian 1992; Potenza et al. 2001). Furthermore, analysis indicates that a greater proportion of such offenders were single or not married/ cohabiting and had a lower level/no qualification compared with the non-offenders. The median salary earnings in the offending group were significantly less than the non-offending group: $£ 6000+$ a year less.

High rates of mental illness were found in both groups (Table 2). There was a statistically significant increase in a mental health diagnosis, a family history of mental health problems and previous gambling disorder treatment within the offending group when compared with the non-offending group. Moreover, a higher proportion of those in the offending group had experienced childhood abuse, specifically sexual abuse and multiple abuse compared with the non-offending group. A series of further Mann-Whitney $U$ test showed clients who reported offending behaviour scored significantly higher on the PGSI, PHQ-9 and GAD-7 indicating increased severity of gambling, depression and anxiety (see Table 3).

Table 3 Clinical scores

\begin{tabular}{llllr}
\hline Variable & $\begin{array}{l}\text { Non-offending } \\
\text { Median (IQR) }\end{array}$ & $\begin{array}{l}\text { Offending } \\
\text { Median (IQR) }\end{array}$ & Statistical test & $P$ value \\
\hline PGSI & $20(7)$ & $23(7)$ & $U=116,092$ & 0.001 \\
PHQ-9 & $11(12)$ & $14(11)$ & $U=123,183$ & 0.001 \\
GAD-7 & $10(10)$ & $11(10)$ & $U=124,315$ & 0.001 \\
\hline
\end{tabular}


Table 4 Gambling history

\begin{tabular}{lllllll}
\hline Variable & \multicolumn{2}{l}{ Non-offending } & \multicolumn{2}{l}{ Offending } & Statistical test & $P$ value \\
& $n$ & $\%$ & $n$ & $\%$ & & \\
Early big win & 341 & 50.20 & 280 & 55.60 & $\chi^{2}(1, n=1183)=3.301$ & 0.069 \\
Loss of job due to gambling & 86 & 12.40 & 131 & 25.70 & $\chi^{2}(1, n=1205)=35.304$ & 0.001 \\
Loss of relationship due to gambling & 222 & 32.10 & $211 \quad 41.30$ & $\chi^{2}(1, n=1202)=10.705$ & 0.001 \\
& Median (IQR) & Median (IQR) & Statistical test & $P$ value \\
Days gambled in past month & $15(17)$ & $20(15.75)$ & $U=108,721$ & 0.028 \\
Money lost in past month & $£ 1500(£ 2900)$ & $£ 1500(£ 2500)$ & $U=111,176$ & 0.097 \\
Current debt & $£ 6000(£ 19,700)$ & $£ 5000(£ 14,600)$ & $U=156,200$ & 0.315 \\
Total losses & $£ 40,000$ & $£ 40,000$ & $U=144,696$ & 0.871 \\
Age at first gamble & $(£ 90,000)$ & $(£ 97,000)$ & & \\
\hline
\end{tabular}

Overall, those who reported offending behaviour to finance gambling started gambling at a significantly significant earlier age (by 2 years) and had gambled more days in the month before treatment started (Table 4). This group of offenders were more likely to have lost a job and a relationship due to gambling. Between groups, there was no significant difference between amount of current debt and the median total losses.

The functional relationship between gambling and crime in multifaceted, and there is no consensus as to the link (Adolphe et al. 2019). A range of theoretical perspectives has been proposed, such as that crime is committed to subsidise gambling or gambling-related debt (Blaszczynski and McConaghy 1994), that antisocial personality characteristics and ultimately criminal behaviour surface due to the stress of gambling debt and the need for it to remain hidden from significant others (Blaszczynski and McConaghy 1991), that gambling can be considered an activity synchronous with other unlawful endeavours (Meyer and Stadler 1999) or that other factors may mediate the relationship such as a disinhibiting co-occurring substance use or impulsivity disorder (Preston et al. 2012). Notwithstanding the range of theoretical perspectives, as suggested by Perrone et al. (2013), May-Chahal et al. (2017) and Lahn and Grabosky (2003), the links can be differentiated by three principal explanations: First, that there is an instrumental link between crime and gambling, where, for example acquisitive crime may be used to get money to gamble or to pay off a gambling-related debt (Blaszczynski and McConaghy 1991). Second, the presence of a co-symptomatic link in that gambling and offending stem from the same underlying disorder (such as a comorbid disorder) (Blaszczynski and Silove 1996) and third a coincidental link (no relationship between the two) (Blaszczynski and McConaghy 1994).

Our findings correspond more closely to the first two links. Individuals explicitly admitted to committing crime to finance gambling, indicative of an instrumental link. Unmanageable debt has been shown to be a serious outcome of disordered gambling (Downs and Woolrych 2009,2010 ) and can lead to a range of social harms that go beyond the individual including criminality (Langham et al. 2015). A major risk factor for gambling-related criminality has been shown to be excessive financial problems (Ledgerwood et al. 2007; Momper et al. 2010; Potenza et al. 2000). Once an individual who is in debt depletes all the legal opportunities to obtain money (e.g. salary, loans), they become anxious and depressed, and may become preoccupied with obtaining money that they seek alternative and potentially illegal means to obtain money as judgement is compromised (Rosenthal and Lesieur 1996).

The study established that there was a significant difference between those who had offended and those who had not; participants who report gambling-related offending had 
more severe psychopathology compared with clients who reported none (suggestive of a cosymptomatic link). A greater proportion of the offending group had a lifetime mental health diagnosis, had previous gambling disorder treatment and greater anxiety, depression and problem gambling scores. These results are in accordance with previous studies that have demonstrated that disordered gamblers with a history of arrest or criminal record show increased gambling-related problem symptomology (Ledgerwood et al. 2007; Mestre-Bach et al. 2018b; Potenza et al. 2000) and are more likely to have depressive symptoms (Momper et al. 2010) or anxiety (Ellis et al. 2018) and have received mental health treatment (Potenza et al. 2000). Such a finding suggests that crimes committed by disordered gamblers may be indicative of a more macro disturbance in the biopsychosocial functioning of those individuals. However, it must be noted that even though the relationship between gambling and crime in our sample is indicative of both an instrumental and co-symptomatic link, the exact framework integrating the two is still unspecified. A framework that can go some way to expounding the link is one that includes impaired impulse control. Pathological gambling has been shown to be associated with elevated impulsivity (Hodgins and Holub 2015) and elevated impulsivity is also associated with criminality (Lynam and Miller 2004). Such a framework would explain why not all individuals with a diagnosis of disordered gambling and related financial problems engage in criminal behaviour. The mediating effect of impulsivity on gambling and crime warrants further exploration.

As well as in a more severe psychopathology, the offending group also had higher rates of childhood abuse (multiple), a family history of mental health difficulties and gambling-related harms such as relationship and job loss. Previous studies have shown that individuals with gambling problems report greater childhood maltreatment and traumatic life events (e.g. Afifi et al. 2010; Hodgins et al. 2010; Roberts et al. 2017). Maltreatment has been shown to significantly increase the likelihood of criminality at a later stage and that the probability strengthens with the experience of several forms of maltreatment (Currie and Tekin 2012). In addition, a higher proportion of the offending group had lost a job or a relationship due to gambling and was more likely to be single/ unmarried. In our group of participants, it is quite probable that the offending carried out may go beyond that explained merely by instrumental or co-symptomatic links but may be mediated by other multiple factors such as distinctive demography, impulsivity and varying clinical and personality traits (Granero et al. 2015), and highlights that criminal behaviour seldom appears in isolation (Petry et al. 2013). The finding also fits with the negative family and life experience in the 'emotionally vulnerable problem' pathway as described in the pathways model of gambling (Blaszczynski and Nower 2002).

The sample of gamblers who had committed crime to finance gambling also spent more days gambling and had an earlier age onset of gambling. Recent research in a gambling treatment-seeking sample revealed that those who started gambling at a younger age reported more severe gambling problems and were more likely to have committed an unreported crime (Sharman et al. 2019. In the pathways model (Blaszczynski and Nower 2002), the third pathway, the 'antisocial impulsivist' problem gambler is characterized by early age onset of gambling, early entry into offences related to gambling, poor interpersonal relationships and general psychopathology. Such a pathway may also go some way to explain our findings. It has been shown that these gamblers have poor treatment compliance rates and respond poorly to intervention (Blaszczynski and Nower 2002). Clinically, this pathway may contain different implications for selecting which treatment interventions and management strategies to carry out (Blaszczynski and Nower 2002). 


\section{Limitations}

Participants were drawn from a treatment-seeking population and this figure may therefore not be an accurate reflection of those with a history of offending and disordered gambling in the general population. We did not corroborate self-reported offending history with official records (e.g. the Police National Computer Database); there is therefore the risk that offending to finance gambling was also underreported. Accordingly, previous research has shown that disordered gamblers are prone to underreporting as they do not always view their behaviour as illegal (Bergh and Kühlhorn 1994) or feel uncomfortable disclosing or fear reprisal (Adolphe et al. 2019). Moreover, we did not ask what type of crime the gamblers committed to finance gambling or whether other crimes had been committed not linked to gambling. Most crimes committed by problem gamblers are non-violent acquisitive crimes, such as fraud, forgery, embezzlement, larceny and tax evasion (Blaszczynski and Silove 1996); it would be useful for any future studies to collect this information.

\section{Conclusion}

Notwithstanding the limitations, this study adds to the increasing evidence that disordered gamblers who offend make up a distinct and complex subgroup and have distinct vulnerabilities. Such findings will be useful to clinicians involved in the assessment and management of problematic gambling. Our study established that within the offending group, illegal acts were linked to gambling severity. In addition, the sample who admitted criminality to finance gambling also had more severe psychopathology, early negative life experiences and added social stressors. Consequently, the gambling-crime relationship appears to be mediated by a diverse array of factors such as impulsivity and may be an indicator of a more acute presentation. As such, rather than targeted therapy at addressing disordered gambling or punitive measures of punishment for offending, there is an argument for a more holistic and collaborative approach that takes all related factors into consideration which could have a significant impact on the client. Clients with disordered gambling could be afforded the same opportunities.

Author Contributions Data collection: $\mathrm{AB}$ and $\mathrm{HBJ}$; analysis and interpretation of data: $\mathrm{AB}, \mathrm{MK}$ and $\mathrm{AR}$; preparation of manuscript: $\mathrm{AR}, \mathrm{MK}, \mathrm{SS}, \mathrm{AB}$ and $\mathrm{HBJ}$; critical revisions: $\mathrm{AR}, \mathrm{MK}, \mathrm{SS}, \mathrm{AB}$ and $\mathrm{HBJ}$.

Funding Information The National Problem Gambling Clinic in London is partly funded by the NHS and partly funded by GambleAware, a charity that receives gambling industry funds and distributes these to treatment agencies in the UK.

Compliance with Ethical Standards This paper involved data collected in the context of a service evaluation. All data were collected in accordance with NHS regulations of standard clinical practice.

Conflict of Interest The authors declare that they have no conflicts of interest.

Informed Consent All procedures followed were in accordance with the ethical standards of the responsible committee on human experimentation (institutional and national) and with the Helsinki Declaration of 1975, as revised in 2000 (5). Informed consent was obtained from all patients for being included in the study. 
Open Access This article is licensed under a Creative Commons Attribution 4.0 International License, which permits use, sharing, adaptation, distribution and reproduction in any medium or format, as long as you give appropriate credit to the original author(s) and the source, provide a link to the Creative Commons licence, and indicate if changes were made. The images or other third party material in this article are included in the article's Creative Commons licence, unless indicated otherwise in a credit line to the material. If material is not included in the article's Creative Commons licence and your intended use is not permitted by statutory regulation or exceeds the permitted use, you will need to obtain permission directly from the copyright holder. To view a copy of this licence, visit http://creativecommons.org/licenses/by/4.0/.

\section{References}

Abbott, M. W., \& McKenna, B. G. (2005). Gambling and problem gambling among recently sentenced women in New Zealand prisons. Journal of Gambling Studies, 21(4), 559-581.

Abbott, M. W., McKenna, B. G., \& Giles, L. C. (2005). Gambling and problem gambling among recently sentenced male prisoners in four New Zealand prisons. Journal of Gambling Studies, 21(4), 537-558.

Adolphe, A., Khatib, L., van Golde, C., Gainsbury, S. M., \& Blaszczynski, A. (2019). Crime and gambling disorders: A systematic review. Journal of Gambling Studies, 35(2), 395-414.

Afifi, T. O., Brownridge, D. A., MacMillan, H., \& Sareen, J. (2010). The relationship of gambling to intimate partner violence and child maltreatment in a nationally representative sample. Journal of Psychiatric Research, 44(5), 331-337.

American Psychiatric Association. (2013). Diagnostic and statistical manual of mental Disorders (DSM-5®). American Psychiatric Pub.

Bergh, C., \& Kühlhorn, E. (1994). Social, psychological and physical consequences of pathological gambling in Sweden. Journal of Gambling Studies, 10(3), 275-285.

Blaszczynski, A., \& McConaghy, N. (1991). Pathological gambling and criminal behaviour. Canberra: Australian institute of Criminology.

Blaszczynski, A. P., \& McConaghy, N. (1994). Criminal offenses in Gamblers Anonymous and hospital treated pathological gamblers. Journal of Gambling Studies, 10(2), 99-127.

Blaszczynski, A., \& Nower, L. (2002). A pathways model of problem and pathological gambling. Addiction, 97(5), 487-499.

Blaszczynski, A., \& Silove, D. (1996). Pathological gambling: Forensic issues. Australian \& New Zealand Journal of Psychiatry, 30(3), 358-369.

Bowden-Jones, H. (2013). Commentary on Petry et al. (2013): Actus Reus - why it matters to pathological gambling treatment. Addiction, 108(3), 582-583.

Brown, R. I. F. (1987). Pathological gambling and associated patterns of crime: Comparisons with alcohol and other drug addictions. Journal of Gambling Behavior, 3(2), 98-114.

Currie, J., \& Tekin, E. (2012). Understanding the cycle childhood maltreatment and future crime. Journal of Human Resources, 47(2), 509-549.

Delfabbro, P. (2013). Problem and pathological gambling: A conceptual review. The Journal of Gambling Business and Economics, 7(3), 35-53.

Downs, C., \& Woolrych, R. (2009). Gambling and debt pathfinder study. Manchester: Research Institute Health and Social Change Occasional Publications.

Downs, C., \& Woolrych, R. (2010). Gambling and debt: The hidden impacts on family and work life. Community, Work \& Family, 13(3), 311-328.

Ellis, J. D., Lister, J. J., Struble, C. A., Cairncross, M., Carr, M. M., \& Ledgerwood, D. M. (2018). Client and clinician-rated characteristics of problem gamblers with and without history of gambling-related illegal behaviors. Addictive Behaviors, 84, 1-6.

Ferris, J. A., \& Wynne, H. J. (2001). The Canadian problem gambling index (pp. 1-59). Ottawa: Canadian Centre on substance abuse.

Folino, J. O., \& Abait, P. E. (2009). Pathological gambling and criminality. Current Opinion in Psychiatry, 22(5), $477-481$.

Granero, R., Fernández-Aranda, F., Aymamí, N., Gómez-Peña, M., Fagundo, A. B., Sauchelli, S., del PinoGutiérrez, A., Moragas, L., Savvidou, L. G., Islam, M. A., \& Tàrrega, S. (2015). Subtypes of pathological gambling with concurrent illegal behaviors. Journal of Gambling Studies, 31(4), 1161-1178.

Grant, J. E., Schreiber, L., Odlaug, B. L., \& Kim, S. W. (2010). Pathologic gambling and bankruptcy. Comprehensive Psychiatry, 51(2), 115-120. 
Hodgins, D. C., \& Holub, A. (2015). Components of impulsivity in gambling disorder. International Journal of Mental Health and Addiction, 13(6), 699-711.

Hodgins, D. C., Schopflocher, D. P., el-Guebaly, N., Casey, D. M., Smith, G. J., Williams, R. J., \& Wood, R. T. (2010). The association between childhood maltreatment and gambling problems in a community sample of adult men and women. Psychology of Addictive Behaviors, 24(3), 548.

Hughes, M. A., Dolan, M. C., \& Stout, J. C. (2014). Regret in the context of unobtained rewards in criminal offenders. Cognition \& Emotion, 28(5), 913-925.

Kroenke, K., Spitzer, R., \& Williams, J. (2001). The PHQ-9: Validitiy of a brief depression severity measure. Journal of General Internal Medicine, 16(9), 606-613.

Ladouceur, R., Boisvert, J. M., Pépin, M., Loranger, M., \& Sylvain, C. (1994). Social cost of pathological gambling. Journal of Gambling Studies, 10(4), 399-409.

Lai, T. K. (2014). Gambling and problem/pathological gambling among ex-offenders in Hong Kong. China Journal of Social Work, 7(1), 39-50.

Lahn, J. (2005). Gambling among offenders: Results from an Australian survey. International Journal of Offender Therapy and Comparative Criminology, 49(3), 343-355.

Lahn, J., \& Grabosky, P. (2003). Gambling and clients of ACT corrections: Final report. Canberra, Australian Capital Territory: Centre for Gambling Research, Regulatory Institutions Network, Australian National University.

Langham, E., Thorne, H., Browne, M., Donaldson, P., Rose, J., \& Rockloff, M. (2015). Understanding gambling related harm: A proposed definition, conceptual framework, and taxonomy of harms. BMC Public Health, 16(1), 80.

Ledgerwood, D. M., \& Petry, N. M. (2004). Gambling and suicidality in treatment-seeking pathological gamblers. The Journal of Nervous and Mental Disease, 192(10), 711-714.

Ledgerwood, D. M., Steinberg, M. A., Wu, R., \& Potenza, M. N. (2005). Self-reported gambling-related suicidality among gambling helpline callers. Psychology of Addictive Behaviors, 19(2), 175-183.

Ledgerwood, D. M., Weinstock, J., Morasco, B. J., \& Petry, N. M. (2007). Clinical features and treatment prognosis of pathological gamblers with and without recent gambling-related behavior. Journal of the American Academy of Psychiatry and the Law, 35, 294-3001.

Lorains, F. K., Cowlishaw, S., \& Thomas, S. A. (2011). Prevalence of comorbid disorders in problem and pathological gambling: Systematic review and meta-analysis of population surveys. Addiction, 106(3), 490-498.

Lorenz, V. C., Politzer, R. M., \& Yaffee, R. A. (1990). Final report task force on gambling addiction in Maryland. Baltimore: Maryland Department of Health and Mental Hygiene, Alcohol and Drug Abuse Administration.

Lynam, D. R., \& Miller, J. D. (2004). Personality pathways to impulsive behavior and their relations to deviance: Results from three samples. Journal of Quantitative Criminology, 20(4), 319-341.

May-Chahal, C., Humphreys, L., Clifton, A., Francis, B., \& Reith, G. (2017). Gambling harm and crime careers. Journal of Gambling Studies, 33(1), 65-84.

Meyer, G., \& Fabian, T. (1992). Delinquency among pathological gamblers: A causal approach. Journal of Gambling Studies, 8(1), 61-77.

Meyer, G., \& Stadler, M. A. (1999). Criminal behavior associated with pathological gambling. Journal of Gambling Studies, 15(1), 29-43.

Mestre-Bach, G., Steward, T., Granero, R., Fernández-Aranda, F., Talón-Navarro, M. T., Cuquerella, À., Baño, M., Moragas, L., del Pino-Gutiérrez, A., Aymamí, N., Gómez-Peña, M., Mallorqui-Bagué, N., VintróAlcaraz, C., Magaña, P., Menchón, J., \& Jiménez-Murcia, S. (2018a). Gambling and impulsivity traits: A recipe for criminal behavior? Frontiers in Psychiatry, 9(6), 1-10.

Mestre-Bach, G., Steward, T., Granero, R., Fernández-Aranda, F., Talón-Navarro, M. T., Cuquerella, À., del Pino-Gutiérrezf, A., Aymamía, N., Gómez-Peña, M., Mallorquí-Baguéa, N., Mena-Morenoa, T., VintróAlcaraza, C., Bañoa, M., Moragasa, L., Magañag, P., José Manuel Menchóna, J. M., \& Susana JiménezMurci, S. (2018b). Sociodemographic and psychopathological predictors of criminal behavior in women with gambling disorder. Addictive Behaviors, 80, 124-129.

Momper, S. L., Delva, J., Grogan-Kaylor, A., Sanchez, N., \& Volberg, R. A. (2010). The association of at-risk, problem, and pathological gambling with substance use, depression, and arrest history. Journal of Gambling Issues, 24, 7-32.

Pachur, T., Hanoch, Y., \& Gummerum, M. (2010). Prospects behind bars: Analyzing decisions under risk in a prison population. Psychonomic Bulletin \& Review, 17(5), 630-636.

Perrone, S., Jansons, D., \& Morrison, L. (2013). Problem gambling and the criminal justice system. Melbourne: Victorian Responsible Gambling Foundation.

Petry, N. M. (2005). Comorbidity of disordered gambling and other psychiatric disorders. Pathological gambling: Etiology, comorbidity and treatment. In N. Petry (Ed.), Pathological gambling: Etiology, comorbidity and treatment. Washington, DC: American Psychological Association.

Petry, N. M., Blanco, C., Stinchfield, R., \& Volberg, R. (2013). An empirical evaluation of proposed changes for gambling diagnosis in the DSM-5. Addiction, 108(3), 575-581. 
Potenza, M. N., Steinberg, M. A., McLaughlin, S. D., Wu, R., Rounsaville, B. J., \& O’Malley, S. S. (2000). Illegal behaviors in problem gambling: Analysis of data from a gambling helpline. Journal of the American Academy of Psychiatry and the Law, 28, 389-403.

Potenza, M. N., Steinberg, M., McLaughlin, S., Wu, R., Rounsaville, B. J., \& O’Malley, S. S. (2001). Genderrelated differences in the characteristics of problem gamblers using a gambling helpline. American Journal of Psychiatry, 158, 1500-1505.

Potenza, M. N., Steinberg, M. A., \& Wu, R. (2005). Characteristics of gambling helpline callers with selfreported gambling and alcohol use problems. Journal of Gambling Studies, 21(3), 233-254.

Preston, D. L., McAvoy, S., Saunders, C., Gillam, L., Saied, A., \& Turner, N. E. (2012). Problem gambling and mental health comorbidity in Canadian federal offenders. Criminal Justice and Behavior, 39(10), 1373-1388.

Riley, B. J., Larsen, A., Battersby, M., \& Harvey, P. (2018). Problem gambling among Australian male prisoners: Lifetime prevalence, help-seeking, and association with incarceration and aboriginality. International Journal of Offender Therapy and Comparative Criminology, 62(11), 3447-3459.

Roberts, A., Coid, J., King, R., Murphy, R., Turner, J., Bowden-Jones, H., Du Preez, K. P., \& Landon, J. (2016). Gambling and violence in a nationally representative sample of UK men. Addiction, 111(12), 2196-2207.

Roberts, A., Landon, J., Sharman, S., Hakes, J., Suomi, A., \& Cowlishaw, S. (2018). Gambling and physical intimate partner violence: Results from the national epidemiologic survey on alcohol and related conditions (NESARC). American Journal on Addictions, 27(1), 7-14.

Roberts, A., Sharman, S., Coid, J., Murphy, R., Bowden-Jones, H., Cowlishaw, S., \& Landon, J. (2017). Gambling and negative life events in a nationally representative sample of UK men. Addictive Behaviors, $75,95-102$.

Rosenthal, R. J., \& Lesieur, H. R. (1996). Pathological gambling and criminal behavior Explorations in criminal psychopathology: Clinical syndromes with forensic implications 149-169.

Sakurai, Y., \& Smith, R. G. (2003). Gambling as a motivation for the commission of financial crime. Canberra: Australian Institute of Criminology.

Sharman, S., Dreyer, J., Aitken, M., Clark, L., \& Bowden-Jones, H. (2015). Rates of problematic gambling in a British homeless sample: A preliminary study. Journal of Gambling Studies, 31(2), 525-532.

Sharman, S., Murphy, R., Turner, J., \& Roberts, A. (2019). Psychosocial correlates in treatment seeking gamblers: Differences in early age onset gamblers vs later age onset gamblers. Addictive Behaviors, 97, 20-26.

Spitzer, R., Kroenke, K., Williams, J., \& Lowe, B. (2006). A brief measure for assessing generalized anxiety disorder: The GAD-7. Archives of Internal Medicine, 166(10), 1092-1097.

Turner, N. E., Preston, D. L., McAvoy, S., \& Gillam, L. (2013). Problem gambling inside and out: The assessment of community and institutional problem gambling in the Canadian correctional system. Journal of Gambling Studies, 29(3), 435-451.

Turner, N. E., Preston, D. L., Saunders, C., McAvoy, S., \& Jain, U. (2009). The relationship of problem gambling to criminal behavior in a sample of Canadian male federal offenders. Journal of Gambling Studies, 25, 153169.

Varghese, F. P., Charlton, S. R., Wood, M., \& Trower, E. (2014). Temporal discounting and criminal thinking: Understanding cognitive processes to align services. Psychological Services, 11(2), 171-178.

Wardle, H., Moody, A., Spence, S., Orford, J., Volberg, R., Jotangia, D., Griffiths, M., Hussey, D., \& Dobbie, F. (2011). British Gambling Prevalence Survey 2010. Prepared for the gambling commission. London: National Centre for Social Research.

Williams, R. J., Royston, J., \& Hagen, B. F. (2005). Gambling and problem gambling within forensic populations: A review of the literature. Criminal Justice and Behavior, 32(6), 665-689.

Williams, R. J., \& Volberg, R. A. (2014). The classification accuracy of four problem gambling assessment instruments in population research. International Gambling Studies, 14(1), 15-28.

Williams, R. J., Volberg, R. A., \& Stevens, R. M. (2012). The population prevalence of problem gambling: Methodological influences, standardized rates, jurisdictional differences, and worldwide trends. Ontario Problem Gambling Research Centre.

Yechiam, E., Kanz, J. E., Bechara, A., Stout, J. C., Busemeyer, J. R., Altmaier, E. M., \& Paulsen, J. S. (2008). Neurocognitive deficits related to poor decision making in people behind bars. Psychonomic Bulletin \& Review, 15(1), 44-51.

Zorland, J., Moss, A., Perkins, A., \& Emshoff, J. (2008). Gambling and offending: An examination of the literature. Georgia State University.

Publisher's Note Springer Nature remains neutral with regard to jurisdictional claims in published maps and institutional affiliations. 